\title{
Evaluation of the S.T.O.N.E Score to Predict the Outcomes of Flexible Ureteroscopy for Urinary Stones
}

\section{Maatougui Jasser*, Raboudi Mehdi, Ben Rejeb Nedhir, Khiari Ramzi and Ghozzi Samir}

Department of Urology, Military Hospital of Tunis, University of Tunis El Manar, Tunisia

*Corresponding Author: Maatougui Jasser, Department of Urology, Military Hospital of Tunis, University of Tunis El Manar, Tunisia.
Received: November 22, 2021

Published: January 12, 2022

(C) All rights are reserved by Maatougui Jasser., et al.

\section{Abstract}

Over the years, several nomograms have been developed to predict the rate of no fragments after surgery for urinary stones. The objective of this work is to evaluate the S.T.O.N.E score to predict of the effectiveness of flexible ureteroscopy for urolithiasis.

The S.T.O.N.E score evaluates 5 parameters: S (Size): size, T (Topography): location, 0 (Obstruction): obstruction, N (Number), calculation number, E (Evaluation of Hounsfield Unit) computation density in Hounsfield unit. A score of 1 to 3 points is assigned to each parameter. Between January 2015 and December 2019, 92 interventions were performed. The S.T.O.N.E score was calculated retrospectively for each patient and correlated with the absence of residual fragment 3 months after flexible ureteroscopy (SFR: Stone Free Rate). We tried to determine the threshold value of this score through the analysis of the receiver operator curve.

The average S.T.O.N.E Score was 9.94. The Stone free rate was 81\%. After statistical analysis, the area below the ROC curve was 0.73 IC-95\% [0.624; 0.836]. In our study, a threshold of 10 or less was associated with an SFR of 59.3\%. In comparison, a preoperative S.T.O.N.E Score strictly greater than 10 was associated with a significantly low stone free rate of 39.3\%, $p=0.003$.

In light of our results, the S.T.O.N.E score seems to be an easy, reliable and reproducible tool to predict the outcome of a flexible ureteroscopy.

Keywords: Nomograms; Flexible Ureteroscopy; Urinary Stones

\section{Introduction}

For the past fifteen years, flexible ureteroscopy has become an option of choice in the management of urolithiasis thanks to its remarkable efficiency and low morbidity. Its cost limits its accessibility and restricts its indications in certain socio-economic contexts. Over the years, several nomograms have been developed to predict the rate of no fragments after surgery for urinary stones.

The aim of this work is to evaluate the S.T.O.N.E score as a tool to predict the effectiveness of the flexible ureteroscopy for urolithiasis.

\section{Methods}

Between January 2015 and December 2019, 92 interventions were performed. The S.T.O.N.E score was calculated retrospectively for each patient. This score is a way to objectify the complexity of the calculation in order to predict the effectiveness of the therapeutic procedure used. This score evaluates 5 parameters: S (Size), $\mathrm{T}$ (Topography), $\mathrm{O}$ (Obstruction), $\mathrm{N}$ (Number), E (Evaluation of Hounsfield Unit). A score of 1 to 3 points is assigned to each parameter. A score ranging from 5 to 15 points depending on the characteristics of their calculations is assigned for each patient (Table 1). 


\begin{tabular}{|l|c|c|c|}
\hline Tize & 1 point & 2 points & 3 points \\
\hline Topography & $<5 \mathrm{~mm}$ & $5-10 \mathrm{~mm}$ & $>10 \mathrm{~mm}$ \\
\hline Obstruction & $\begin{array}{c}\text { Distal } \\
\text { ureteral } \\
\text { obstruction } \\
\text { or } \\
\text { preoperative } \\
\text { Stenting }\end{array}$ & $\begin{array}{c}\text { Proxima } \\
\text { ureteral } \\
\text { Renal (except } \\
\text { inferior caliceal) }\end{array}$ & $\begin{array}{c}\text { Minimal or } \\
\text { moderate } \\
\text { obstruction } \\
\text { rior caliceal }\end{array}$ \\
\hline Numbre & 1 & $\begin{array}{c}\text { Major } \\
\text { obstruction }\end{array}$ \\
\hline Density (UH) & $<750 \mathrm{UH}$ & $750-1000 \mathrm{UH}$ & $>1000 \mathrm{UH}$ \\
\hline
\end{tabular}

Table 1: S.T.O.N.E score settings.

The S.T.O.N.E. score calculated for each patient was correlated with the absence of residual fragment 3 months after the intervention using a logistic regression model. The analysis of the receiver operator curve allowed us to determine the threshold value of the S.T.O.N.E score.

\section{Results}

The average age of our patients was 50 years with extremes ranging from 20 to 82 years (Figure 1). Sex ratio was $1.63 \mathrm{M} / \mathrm{F}$ with 57 men (62\%) and 35 women (38\%) (Figure 2).

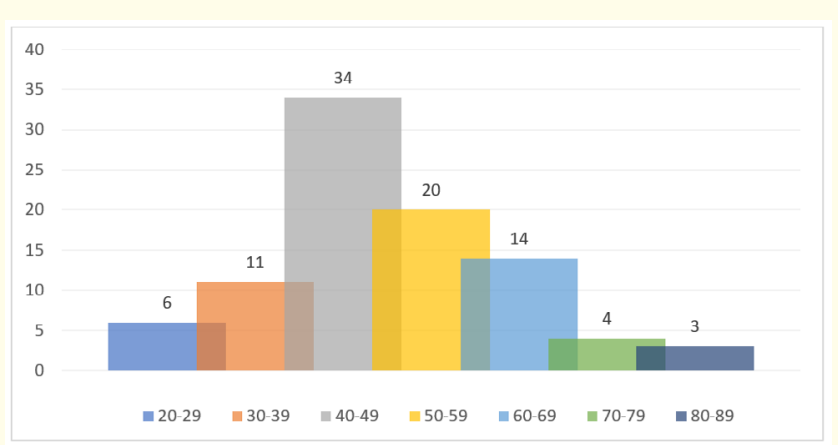

Figure 1: Distribution of patients by age group.

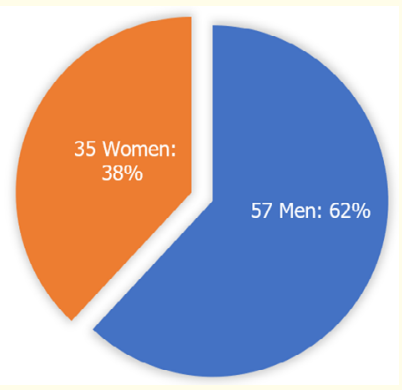

Figure 2: Distribution of patients by sex.
The total number of operated stones made was 162 . In $53 \%$ of cases, the stone was unique. In $29 \%$ of the cases, there were 2 stones and in $18 \%$ we found at least 3 stones. The average size was $17.7 \mathrm{~mm}$ [15-26 mm]. In $30 \%$ of cases, the largest stone sizes exceeded $20 \mathrm{~mm}$. The average density found is: $1000 \mathrm{UH}$ [350-1950]. The average S.T.O.N.E. score was 12 [min: 7 - max: 13]. The table shows the distribution of patients by S.T.O.N.E score where $40 \%$ of patients had a score of 9 or less. The majority of patients (59\%) scored above or equal to 10 (Table 2).

\begin{tabular}{|l|c|c|}
\hline S.T.O.N.E Score & Number & Percentage \\
\hline 7 & 4 & $4 \%$ \\
\hline 8 & 15 & $16 \%$ \\
\hline 9 & 18 & $21 \%$ \\
\hline 10 & 22 & $24 \%$ \\
\hline 11 & 15 & $16 \%$ \\
\hline 12 & 14 & $15 \%$ \\
\hline 13 & 4 & $4 \%$ \\
\hline 14 & 0 & 0 \\
\hline 15 & 0 & 0 \\
\hline
\end{tabular}

Table 2: Distribution of patients by S.T.O.N.E score.

The average S.T.O.N.E Score found in our series was 9.94 for a Stone free rate of $81 \%$. After statistical analysis, the area below the ROC curve is 0.73 (Figure 2), IC-95\% [0.624; 0.836]. In our study, a threshold of 10 or less is associated with a stone free rate of $59.3 \%$. Comparatively, a preoperative S.T.O.N.E Score strictly greater than 10 was associated with a significantly different stone free rate of $39.3 \%$ (Table 3).

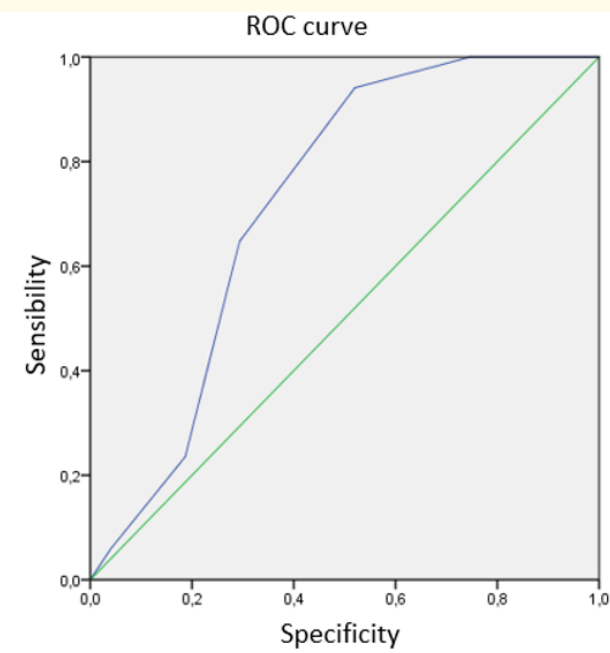

Figure 3: Correlation between S.T.O.N.E score and stone free rate in ROC. (AUC -0.73). 


\begin{tabular}{|l|c|c|c|c|c|}
\hline & & & \multicolumn{2}{|c|}{$\begin{array}{c}\text { Confidence } \\
\text { interval }\end{array}$} \\
\cline { 5 - 6 } & AUC & Threshold & $\begin{array}{c}\mathbf{P} \\
\text { value }\end{array}$ & $\begin{array}{c}\text { Lower } \\
\text { bound }\end{array}$ & $\begin{array}{c}\text { Upper } \\
\text { bound }\end{array}$ \\
\hline Stone score & 0,730 & 10 & 0,003 & 0,624 & 0,836 \\
\hline
\end{tabular}

Table 3: Correlation between S.T.O.N.E score and stone free rate in ROC.

According to our study, an S.T.O.N.E Score of less than 10 was considered to be predictive of the efficiency of flexible ureteroscopy $(\mathrm{p}<0.003)$.

\section{Discussion}

Computed tomography provides the urologists with valuable information about urinary tract and stones characteristics such as, number, size, density [2]. These characteristics had been analysed by several nomograms. Among these nomograms, the S.T.O.N.E score which was first proposed by Molina [1] in 2014, seems to be valuable predict the success of surgical or endoscopic treatment of urinary stones.

In a series of 200 patients published by Wislon in 2014, an S.T.O.N.E score of 9 or less was associated with a $90 \%$ stone free rate [1]. In our series, the threshold of S.T.O.N.E found score was 10 with a stone free rate of $59.3 \%$. The statistical analysis of our cohort found a statistically significant difference in stone score in stone free patients (score at 9.8) compared to patients with residual stones after the flexible ureteroscopy (score at 10.4; $<<0.003$ ).

This score was also applied for percutaneous nephrolithotomy (PCNL). In a retrospective study published in 2015 involving 185 patients, Noureldin found a significant difference between the STONE score of stone free patients and the score of those with residual stones (7.4 versus 8.3; $\mathrm{p}=0.004$ ). Logistic regression analysis found that this score was statistically correlated with post-operative free stone rate [3].

In addition, Okhunov had found that this score had a significant impact on estimated blood loss ( $p=0.005)$, the duration of an PCNL ( $p-0.001)$ and the length of hospitalization ( $p=0.001)$. However, this author had not found a statistically significant correlation between this score and post-PCNL complications [4].
Some authors had criticized some limitations to the S.T.O.N.E score. For example, this nomogram did not include the patient's urological history, anatomical abnormalities of the urinary tract, and difficulties and peroperative incidents that could significantly influence the post-operative outcomes [5].

In addition, other nomograms had been proposed. For example; The R.U.S.S. score (Resorlu Unsal Stone Score), the S.R.E.S.C modified (Seoul National University Renal Complexity) and the Ito score. In a study published by Richard in 2020 [6] whose objective was to compare these different scores in terms of predictive value of the success of the flexible ureteroscopy, the Ito score had a better sensitivity compared to other scores (AUC - 0.735, [95\% CI: 0.692-0.777]).

The main limitation of our work is its retrospective nature. The second limitation is the small size of our serie. The assessment of the size of the stones before the intervention and that of the residual fragments was not carried out by the same radiological examination, which may be the cause of the biases because, apart from the scanners, the ultrasound and the AUP lack the sensitivity and specificity to evaluate the calculations of the upper urinary tract. Moreover, not all procedures were performed by the same surgeon, which can lead to variations in the result depending on the experience of each operator.

Analysis of the factors influencing stone free is essential to help the urologist to choose the best therapeutic approach for each patient. To our knowledge, there are few studies that have been interested in studying the correlation between the complexity of high urinary tract stones and stone free status after flexible ureteroscopy. We propose this score to predict the effectiveness of flexible ureteroscopy in the management of urinary stones.

\section{Conclusion}

The S.T.O.N.E score appears to be a reliable and reproducible tool for better patient selection to optimize the effectiveness of flexible ureteroscopy for urinary stones.

\section{Data Availability}

Data availability is accessible on demand.

\section{Conflicts of Interest}

The authors declare that they have no conflicts of interest. 


\section{Author Contributions}

Maatougui Jasser: acquisition of data and drafting the manuscript. Raboudi Mehdi: Analysis and interpretation of data, critical revision of the manuscript. Khiari Ramzi and Ghozzi Samir: supervision.

\section{Bibliography}

1. Molina W., et al. "The S.T.O.N.E. Score: A new assessment tool to predict stone free rates in ureteroscopy from pre-operative radiological features". International Brazilian Journal of Urology 40.1 (2014): 23-29.

2. Lechevallier E., et al. "Imagerie et calcul de la voie excrétrice urinaire supérieure". Progress in Urology 18.12 (2008): 863867.

3. Noureldin YA., et al. "Which is better? Guy's versus S.T.O.N.E. nephrolithometry scoring systems in predicting stone-free status post-percutaneous nephrolithotomy". World Journal of Urology 33.11 (2015): 1821-1825.

4. Okhunov Z., et al. "Interobserver reliability and reproducibility of S.T.O.N.E. nephrolithometry for renal calculi". Journal of Endourology 27 (2013b): 1303-1306.

5. Jiang K., et al. "Evaluation of three stone-scoring systems for predicting SFR and complications after percutaneous nephrolithotomy: a systematic review and meta-analysis". BMC Urology 19 (2019): 57.

6. Richard F., et al. "Evaluation and comparison of scoring systems for predicting stone-free status after flexible ureteroscopy for renal and ureteral stones". PLoS One 15.8 (2020).

\section{Assets from publication with us}

- Prompt Acknowledgement after receiving the article

- Thorough Double blinded peer review

- Rapid Publication

- Issue of Publication Certificate

- High visibility of your Published work

Website: $\underline{w w w}$.actascientific.com/

Submit Article: www.actascientific.com/submission.php

Email us: editor@actascientific.com

Contact us: +919182824667 